\title{
Identidad institucional. El Tribunal Electoral ante las elecciones presidenciales de 2000
}

\author{
David H. Corrochano*
}

\begin{abstract}
The construction of a positive identity is a basic condition so that the institutions provide stability and confidence to the political system. In this paper we analyze the identity of the Electoral Tribunal of Federal Judicial Power (TEPJF) in the 2000 electoral moment, because it is an example of an institution without identity, moving between positive and negative images and involved in a critical situation (what we could call an "institutional scandal"). The difficulty of society to make a difference between this institution and other ones endangered the stability of the Mexican political system and the confidence in the democratizing change process.
\end{abstract}

Keywords: institutional identity, political scandal, institutional blackmail.

\section{Resumen}

La construcción de una identidad positiva es una condición básica para que las instituciones doten de estabilidad y confianza al sistema político. En este artículo analizamos la identidad del Tribunal Electoral del Poder Judicial de la Federación (TEPJF) en la coyuntura electoral del 2000, porque sirve como ejemplo de una institución sin identidad, que oscila entre evocaciones positivas y negativas, que se vio en una situación crítica (lo que podemos llamar un "escándalo institucional”). La dificultad de la sociedad para diferenciar a esta institución de otras puso en peligro la estabilidad del sistema político mexicano y la confianza en el proceso de cambio democratizador.

Palabras clave: identidad institucional, escándalo político, chantaje institucional.

* Facultad Latinoamericana de Ciencias Sociales-México. Correo electrónico: davcorr@flacso.flacso.edu.mx 


\section{Introducción ${ }^{1}$}

El cambio político no sólo se basa en la construcción de nuevas instituciones sino en que éstas conformen una identidad positiva por la que sean identificables, confiables y legítimas para la sociedad. Si consideramos la confianza como una variable endógena al cambio institucional (Schedler, 1999: 105-106) lo que tratamos de demostrar es que está determinada por el tipo de identidad social, positiva o negativa, que adquieren las instituciones frente a la sociedad. La confianza en el sistema político se constituye a partir de la adopción de "reglas de conducta pertinentes", pero también a través de la concreción de "expectativas de justificación" que alimentan la legitimidad social de las instituciones (March y Olsen, 1997: 75-76), es decir, el grado en que satisfacen subjetivamente determinadas expectativas sociales "a través de acciones que proveen evidencias de consenso" (Beetham, 1992: $18)$.

De manera laxa, en este artículo entenderemos por institución "una organización política o procedimiento pensado para mantener el orden, resolver litigios, elegir líderes y promover de este modo una forma de convivencia entre grupos sociales enfrentados" (Cansino, 2000: 62). Nuestro interés es analizar el grado y tipo de identidad institucional alcanzado por el Tribunal Electoral del Poder Judicial de la Federación (TEPJF) en la coyuntura de las elecciones presidenciales del 2 de julio del 2000. Para ello, partimos de la premisa de que existe un complejo juego de interacciones entre la sociedad y las instituciones en el que éstas pueden generar "su propio ímpetu" (Putnam, 1994: 25) al momento de construir su identidad, es decir, al concretar los límites que las caracterizan para influir, a partir de aquí, en la visión y el comportamiento de la sociedad frente al sistema político.

Por identidad institucional entendemos tres aspectos interrelacionados: primero, la capacidad que tiene una institución de ser conocida por la ciudadanía, es decir, el grado en que los límites normativos que la diferencian de otras instituciones del Esta-

\footnotetext{
${ }^{1}$ Este artículo es resultado de la participación del autor en la investigación "Proyecto estratégico para el fortalecimiento de la imagen positiva del TEPJF frente a las elecciones del 2000", coordinado por el Dr. Héctor Díaz Santana y dirigido por el Dr. Germán Pérez Fernández del Castillo. Todo lo que aquí está incluido es responsabilidad única de su autor, quien coordinó las áreas metodológica y de análisis de prensa en esta investigación. Hay que agradecer la labor de la Mtra. Citlali Villafranco al momento de trabajar en la presentación de este texto y, por supuesto, los inestimables comentarios del Dr. Henio Millán a la versión preliminar de este artículo.
} 
do son apreciados por la sociedad y/o están acompañados de atributos particulares por los cuales logra ser una organización identificable; segundo, la relación entre esta diferenciación y la confiabilidad de la institución, esto es, el grado en que sus características determinan un curso predecible y positivo a sus acciones (expectativas de buen desempeño); y tercero, el grado en que esta confianza se traduce en legitimidad social, comprendida como la aceptación de la institución no sólo en términos de su origen y procedimientos (el derecho) sino, más bien, en tanto sus acciones y resultados en efecto responden adecuadamente a los deseos y expectativas de la sociedad. La construcción de identidad institucional marca la diferencia fundamental entre identidades positivas (instituciones socialmente legítimas) y negativas (instituciones socialmente ilegítimas).

Nuestra hipótesis es que el TEPJF, durante las elecciones del 2 de julio de 2000, carecía de identidad: era una institución desconocida por la sociedad, y sin confianza ni legitimidad en los términos descritos hasta ahora, lo que implicaba problemas de confianza para el sistema político en general y, en particular, para el proceso electoral.

Este artículo se divide en tres apartados: en el primero, haremos una breve descripción del proceso de cambio político en México con el fin de resaltar la importancia que tiene la identidad institucional para el logro de confianza en el sistema político; en el segundo, analizaremos la coyuntura electoral del 2000 a partir del caso Fox versus TEPJF para ver cómo la ausencia de identidad del tribunal pudo convertirse en un problema para la estabilidad del sistema y el proceso de cambio democratizador; y en el tercero, demostraremos cómo se articuló la ausencia de identidad del TEPJF comparado con otra serie de instituciones del Estado, más concretamente el Instituto Federal Electoral (IFE) como representante de una identidad positiva y los tribunales ordinarios de justicia como encarnación de una identidad negativa.

\section{Identidad institucional y cambio político en México}

El problema de la identidad institucional es básico para las democracias en tanto "la importancia de conocer qué piensa el público estriba en que la complacencia de la voluntad popular aún es, después de todo, la piedra angular sobre la que descansa el edificio del gobierno representativo" (Jiménez, 1994: 23). Esto es más notable en un caso como el mexicano dado el alto grado de 
ambigüedad que, durante años, se mantuvo entre el régimen político formal y el funcionamiento real del sistema político. Lo que queremos resaltar en este apartado es cómo la construcción de identidad positiva fue una necesidad fundamental para la consecución del cambio político mexicano.

Pablo González Casanova, en La democracia en México (1976), articuló la tensión existente entre un régimen político declaradamente democrático y unos usos políticos que redundaban en un monopolio de poder. Esto hizo que el sistema político mexicano recibiera diversos apelativos, como populista o bonapartista, que intentaban describir su naturaleza contradictoria pero, al fin y al cabo, no democrática (Molinar, 1993). En este sentido, consideramos que el concepto de autoritarismo desarrollado por Juan José Linz (1970) es el que engloba las dos características más sobresalientes del régimen político mexicano: institucionalizar un pluralismo limitado y contar con una mentalidad, que no ideología, como guía de acción. Es decir, configurarse a través de lo que Giovanni Sartori (1995) denomina un sistema de partido hegemónico pragmático. ${ }^{2}$

El mantenimiento de este sistema determinó un proceso de desvirtuación institucional porque instituciones típicamente democráticas servían, paradójicamente, para estabilizar una situación autoritaria. Esto es notable para las instituciones electorales, en las que nos centraremos en este apartado, pues nunca sirvieron para canalizar procesos de alternancia e institucionalizar una competencia partidaria sino, contrariamente, para legitimar a través de las urnas un sistema autoritario en el que el partido oficial era el único competidor efectivo. Las instituciones electorales y sus transformaciones, cuando menos hasta 1977, estuvieron al servicio de la clase política oficial y el mantenimiento del autoritarismo (Molinar, 1996: 44-47).

La identidad de las instituciones autoritarias no puede ser calificada como negativa hasta la década de los años sesenta. A su identificación por parte de la sociedad se unían ciertos grados de confianza (manutención del orden y desarrollo) y legitimidad (aceptación de procedimientos y resultados autoritarios), articulados a través de una "cultura política ambigua" capaz de discriminar entre el deber ser y lo práctico para relacionarse con el

\footnotetext{
${ }^{2}$ Hay que advertir que la definición de J. J. Linz incluye un tercer aspecto característico de los regímenes autoritarios: la desmovilización de la sociedad. En este sentido, México escapa de la definición de autoritarismo al constituirse como un régimen que contó con una movilización esporádica y controlada (Labastida, 1977).
} 
sistema político (Durand, 1997). Sin embargo, las crisis de gobernabilidad que enfrentó el autoritarismo desde 1958 (Pérez, 1991) demostraban que la tensión existente entre el régimen normativo y los usos políticos era insostenible a largo plazo, es decir, que la desvirtuación institucional estaba generando paulatinamente instituciones con una identidad negativa.

Este desgaste institucional comienza a manifestarse en las urnas y solucionarse con reformas electorales, es decir, a través de reajustes entre el régimen normativo y las expectativas sociopolíticas. Pese a que la correlación entre voto y determinados estratos sociales no pueda interpretarse de manera directa (Estévez y Ramírez 1985), desde principios de los años sesenta hay un crecimiento del abstencionismo y el voto opositor entre los estratos y zonas más modernizadas de la sociedad (Ames, 1970; Segovia, 2000; Pereyra, 1984; Ramos Oranday, 1985). En 1963, 1973 y 1977 se efectúan tres reformas electorales que venían a ampliar los espacios para la oposición al régimen autoritario, respondiendo así al desgaste de los canales de representación, ${ }^{3}$ de manera especial los canales corporativos (Pacheco y Reyes, 1987). Pese a que estas reformas suponen un importante paso hacia la liberalización del sistema, la ausencia de confianza no sólo persistía, sino que comenzó ha hacerse más notable dada la continuidad del control oficial sobre el proceso de cambio y las propias instituciones.

En 1982 el sistema autoritario sufrió una severa crisis de legitimidad relacionada con el fin del Estado desarrollista y la identidad negativa en que se vieron envueltas las instituciones políticas, más concretamente la institución presidencial dada la decisión discrecional de nacionalizar la banca privada (Gil, 1984). Esta situación fue canalizada a través de la reforma del Estado donde destacó, en el ámbito electoral, la reforma de $1986 .{ }^{4}$

${ }^{3}$ Las reformas de 1963, 1973 y 1977 tuvieron como propósito fortalecer a la oposición leal al régimen, hacer más inclusivos los órganos electorales e incorporar nuevas organizaciones dentro del sistema. La reforma del 63 tuvo como puntos básicos la reducción de los impuestos a los partidos, la posibilidad de que éstos accedieran a la lista de electores y la inclusión de los denominados diputados de partido elegidos por sistema proporcional en listas cerradas. La reforma de 1973 incluyó dos puntos destacables: dotar de representación a todos los partidos en los órganos electorales y regular, por primera vez, su aparición en los medios de comunicación masiva. Por último, la reforma de 1977 flexibilizó los requisitos para entrar en el sistema formal de partidos y reformó la fórmula de integración de la Cámara de Diputados, lo que incrementó el número de diputados de mayoría y los elegidos por criterio proporcional.

${ }^{4}$ Según José Woldenberg, "El balance de la reforma es contradictorio. Por un lado, el gobierno refuerza su control sobre los procesos electorales, pero, por otro, se avanza en términos de la representación proporcional en la integración de la Cámara de Dipu- 
El contenido contradictorio de ésta ejemplifica la ambigüedad de una etapa en la que, si bien los cambios parecían inevitables, no existían actores más allá del Partido Revolucionario Institucional (PRI) que pudieran canalizarlos de forma ordenada. Aunque la oposición llevaba una década creciendo y rearticulándose, aún no estaba capacitada para competir por el poder o negociar frente a la clase política oficial, lo que hacía que el proceso de cambio y las instituciones 'necesariamente' estuvieran controlados por ésta. Sin embargo, para 1988 el ascenso electoral del Partido Acción Nacional (PAN), especialmente en el norte del país y las áreas urbanas, así como, la escisión sufrida por el PRI -que desembocaría en la creación de una plataforma electoral que agrupó a la izquierda mexicana (el Frente Democrático Nacional) y se concretó, después, en un nuevo partido (el Partido de la Revolución Democrática)- hicieron que los noventa fuera una década de intensos cambios donde un punto básico fue la construcción de instituciones electorales dotadas de una identidad positiva. Es decir, de instituciones capaces de transmitir su adecuación a la pluralidad política con base en una independencia respecto del gobierno y los intereses del partido oficial.

Desde 1988 hubo cuatro reformas electorales (1989-1990, 1993, 1994, 1996) ${ }^{5}$ determinadas por la creación, en 1990, de

tados y en algunas otras materias menores" (Woldenberg, 1992: 116). En cuanto a lo primero, se introdujo una ley de representación proporcional al número de votos en la Comisión Federal Electoral, con lo que el PRI superaba al resto de miembros de la comisión. Además, se otorgó al secretario de gobernación la facultad de nombrar a los presidentes y secretarios de las comisiones locales y distritales, continuó la tradición de la autocalificación por parte de diputados y senadores, y se retiró la fórmula del registro condicionado. En cuanto a lo segundo, se sumaron diputados de representación proporcional, se creó la figura de coaliciones, se aceleraron los procesos de cómputo y se creó el Tribunal de lo Contencioso Electoral.

${ }^{5}$ En 1989-1990 el punto más controvertido fue la adopción de una cláusula de gobernabilidad que beneficiaba al partido que obtenía más votos. En 1993 el PRI propuso desterrar la fórmula, sin embargo, ésta se mantendría de manera que el partido que obtuviera $45 \%$ de votos y 200 diputados uninominales era premiado con 90 diputados de representación proporcional. Lo interesante de esta reforma fue que el PAN y el PRD lograron articular una agenda conjunta que incidió en: la conciliación judicial de las disputas electorales, la introducción de alguna fórmula de representación proporcional en el Senado, la regulación del presupuesto de los partidos de manera más estricta y el cambio de los requisitos para la elección presidencial. La reforma de 1994 se concretó en ocho puntos: reformar la composición de las autoridades electorales, revisar la lista de votantes, introducir un acceso equitativo a los medios de comunicación masiva, legislar la utilización no partidista de los fondos públicos, revisar las aportaciones públicas a los partidos, castigar las restricciones a la libertad política a través del código penal y crear una fiscalía especial para los delitos electorales. En cuanto a la reforma de 1996, tuvo como puntos esenciales: concretar la plena autonomía de las autoridades electorales, formular una nueva ecuación para la representación en la Cámara de Diputados, introducir nuevas figuras jurídicas para la protección de ciudadanos y partidos, 
una institución central en el cambio político mexicano y, especialmente, en la dotación de confianza a los procesos electorales: el Instituto Federal Electoral (IFE). El IFE es el encargado de poner en práctica las elecciones federales desde la confección del padrón de electores hasta el conteo de los votos. Sin embargo, el proceso de construcción de una identidad positiva no inició hasta la reforma de 1996 cuando dicho instituto alcanzó plena autonomía a través de la 'ciudadanización' de su consejo: “dice el artículo 41 constitucional que el IFE es un organismo público autónomo, dotado de personalidad jurídica y patrimonio propios, y es la autoridad en materia electoral, en cuya integración participan el Poder Legislativo, los partidos políticos nacionales y la ciudadanía” (Peschard, 1997).

En un clima de fraude electoral y demanda democratizadora, la dependencia de las instituciones electorales respecto a la Secretaría de Gobernación hizo que las reformas no generaran instituciones con una identidad positiva. Para el IFe, la solución adoptada fue crear una institución autónoma dirigida por un consejo dividido en dos: por un lado, los denominados consejeros ciudadanos; y por otro, los representantes de los partidos políticos. Partiendo de esta nueva estructura, la imagen de la institución frente a la sociedad pudo construirse bajo una idea de independencia que redundó en la confiabilidad de los procesos electorales (Schedler, 1999).

Esto se reforzó con la pérdida de mayoría absoluta del PRI en la Cámara de Diputados en 1997 y el proceso de alternancia en la presidencia de gobierno de 2000, acontecimientos que muestran ante el elector la adecuación de la institución a las demandas ciudadanas aunque, ya en la propia contienda de 2000 y más allá de los resultados, esto se pudiera constatar. La capacidad del IFE de acceder a los medios de comunicación masiva con campañas exitosas donde se potenció el conocimiento, la confianza y legitimidad del ciudadano respecto de la institución es, sin duda, una variable importante en su construcción de identidad (IFE, 2000). Pero el IFE no fue la única institución creada en este proceso.

De 1986 a 1996 la resolución de los conflictos electorales y la calificación de los cargos electos transitó de una naturaleza política a una jurisdiccional. En 1986 se creó el Tribunal de lo Contencioso Electoral y en 1990 el Tribunal Federal Electoral

dotar de mayor equidad a la competencia, incluir la votación libre, universal y directa del jefe de gobierno del D.F., variar las condiciones para el registro de partidos y crear la figura de las agrupaciones políticas nacionales. 
(TRIFE), órgano jurisdiccional capaz de resolver los contenciosos electorales. Sin embargo, aún prevalecía un sistema de resolución mixto en el que las decisiones del tribunal podían ser revisadas por el Colegio Electoral de las cámaras correspondientes de manera que no fue hasta 1993 que desaparecieron estos colegios y, por tanto, la capacidad de que los diputados y senadores autocalificaran su propia elección y pudieran revisar las decisiones del tribunal.

Con el fin de despolitizar definitivamente la resolución de las controversias electorales en 1996 se creó el TEPJF como la institución jurisdiccional que, en última instancia, tiene la capacidad de resolver las impugnaciones sobre los resultados electorales, así como, calificar la elección presidencial (TEPJF, 2000). A partir de este proceso, "el Tribunal ha logrado envolverse (...) en un áurea de imparcialidad judicial. Por lo regular, hasta los perdedores acatan sus decisiones con gracia. Sus fallos no simplemente cierran los procesos de toma de decisiones; cierran la controversia legal sobre el asunto en cuestión. Los actores comprenden las resoluciones del Tribunal como interpretaciones no solamente autoritativas sino auténticas de la ley. Lo que decide el Tribunal no es una lectura más de la ley; es la lectura correcta" (Schedler, 2000: 404-405). Esto resalta la existencia de un compromiso político en torno al tribunal que ayuda a la generación de una identidad positiva, sin embargo, y pese a la importancia de este proceso en la dotación de confianza, el TEPJF ha mantenido un bajo perfil social, es decir, apenas ha tenido presencia pública, lo que en situaciones críticas puede erosionar su legitimidad. ${ }^{6} \mathrm{De}$ este modo, nos preguntamos: ¿hasta qué punto el TEPJF cuenta con una identidad institucional, y cómo afecta esto al sistema y cambio políticos?

\section{La coyuntura electoral de 2000 y el TEPJF: el caso Fox versus TEPJF}

La preocupación sobre la identidad del TEPJF está asociada con la controversia surgida en la precampaña electoral de 2000 entre la institución y el candidato presidencial de la Alianza por el Cambio, Vicente Fox Quesada. Ésta ejemplifica cómo la ausencia de

${ }^{6}$ Comentaba un columnista los días previos a la elección de 2000: "La responsabilidad de la calificación de la elección recaerá [...sobre] el TEPJF, cuyas funciones son prácticamente desconocidas por la sociedad mexicana" (Rafael Abascal, El Financiero, 4 de junio de 2000). 
identidad institucional tiene consecuencias negativas en la confianza hacia el sistema político y su estabilidad, sobre todo cuando un actor político relevante articula una acusación de parcialidad contra la institución. ${ }^{7}$ De este modo, y aunque el TEPJF estuvo envuelto en otra serie de controversias durante la campaña electoral del 2 de julio -la más notable fue con el candidato de la Alianza por México al gobierno del Distrito Federal y posteriormente los casos Yucatán y Tabasco-,${ }^{8}$ hemos decidido centrarnos en un solo ejemplo que resulta ilustrativo de las debilidades de imagen de la institución.

Este proceso fue analizado a través de un seguimiento de prensa en el que la controversia es entendida como un escándalo político, ${ }^{9}$ esto es, "un acto público en el que se pone determinada etiqueta a la identidad de cierto actor, es decir, una ceremonia de degradación de estatus" (Sherman 1989, en Jiménez, 1994: 28). Lo preocupante para el TEPJF no era que, a través del que podemos llamar caso Fox versus TEPJF, la institución pasara de ser una identidad positiva a ser una negativa, sino que esta era la exposición pública más importante a la que se enfrentaba desde su creación, tal como lo muestra la elevada cobertura periodística que tuvo el caso frente al número habitual de noticias que cubrían al tribunal (véase la gráfica I).

La naturaleza de este escándalo no puede ser entendida sin el contexto que lo rodeó: por un lado, tenemos una sociedad sensibilizada frente al fraude electoral y que está dispuesta a asimilar escándalos de este tipo; y por otro, la contienda electoral más cerrada que vivía México en los últimos años y en la que

\footnotetext{
${ }^{7}$ A partir del caso Fox versus TEPJF abundaron comentarios como los que mostramos a continuación: "José Antonio Aguilar, investigador del CIDE, comenta que si no se reconocen los resultados de la elección existiría el riesgo de inestabilidad y conflictos (...) habría intenciones de manipular al TRIFE" (El Universal, 24 abril de 2000); "José Luis de la Peza, presidente del TEPJF observó, con toda razón, que está en riesgo la estabilidad del país" (Agustín Bernal, El Sol de México, 16 mayo de 2000); "El sector empresarial del país exigirá a los partidos políticos un pacto de gobernabilidad (...) el objetivo de este acuerdo es evitar presiones políticas sobre el IFE y el TRIFE" (La Crónica, 17 mayo de 2000); "Poner en tela de juicio la imparcialidad del IFE y del TRIFE resulta una estrategia perversa que podría costar mucho al país el 3 de julio" (Adrián Trejo, El Economista, 2 junio de 2000).

${ }^{8}$ En el primer caso, el TEPJF inhabilitó al Consejo Electoral Estatal de Yucatán e instó a la instalación de un nuevo Consejo bajo la negativa de acatar la decisión del gobernador yucateco Víctor Cervera Pacheco, lo que generó, de nueva cuenta, un clima de inestabilidad previo a las elecciones estatales. Mientras que en el segundo anuló las elecciones a gobernador en Tabasco.

${ }^{9}$ Este rastreo en la prensa lo realizó el Lic. Carlos Maya a partir de los principales diarios de cobertura nacional: Reforma, El Universal, La Jornada, Excélsior, El Sol de México, La Crónica, El Financiero, El Economista, Milenio, Unomásuno, El Heraldo de México y Novedades.
} 


\section{Gráfica I \\ Número de notas en prensa sobre el TEPJF septiembre 1999-febrero 2000}

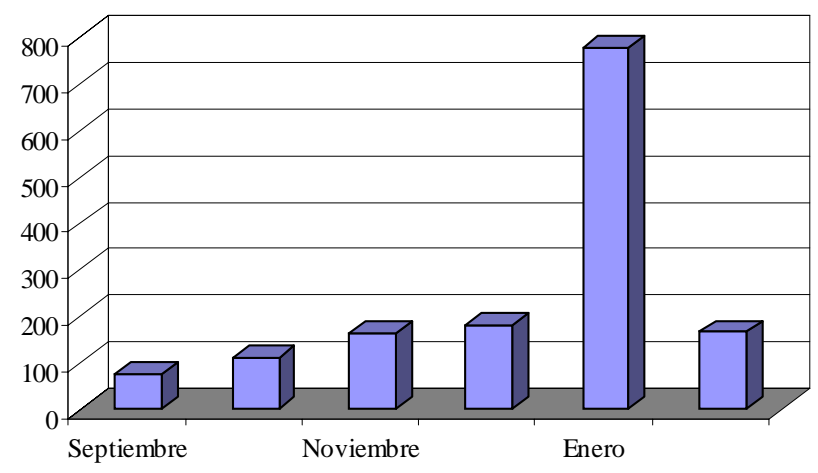

Fuente: Elaboración propia.

Vicente Fox aparecía como un serio contendiente a la presidencia frente al candidato oficial, Francisco Labastida. El caso Fox versus TEPJF tiene cuatro fases:

- Primera, el antecedente del escándalo: momento en que el IFE acepta que el candidato opositor incluya su fotografía en la boleta electoral, y el Partido Auténtico de la Revolución Mexicana, PRD y PRI efectúan una interposición en contra ante el Tribunal; ${ }^{10}$

- Segunda, la presentación del escándalo: la decisión del TEPJF de impedir que la fotografía se incluya en la boleta ${ }^{11}$ y la reacción del candidato quien calificó la decisión como 'una marranada'; ${ }^{12}$

- Tercera, el posicionamiento de los diversos actores implicados: el ataque de Fox y su partido a la decisión del TEPJF, la

${ }^{10}$ Enrique Ibarra, representante del PRI en el IFE, Jesús Ortega, representante del PRD, y Vicente Díaz, del PARM, apoyaron su argumentación en la violación del artículo 205 del COFIPE sobre el diseño de las boletas (véase La Jornada, 22 de diciembre de 1999).

${ }^{11}$ Sobre la razón jurídica de la sentencia véase la entrevista realizada al presidente del TEPJF en La Jornada, 12 enero 2000.

${ }^{12}$ El ataque de Vicente Fox al TEPJF fue considerado como "el precedente más negativo" en la contienda electoral (Miguel Valdés, El Sol de México y La Prensa, 11 de mayo de 2000) dadas las declaraciones del candidato en referencia a los magistrados: "Tal parece que les pagan para echar rollo y trabajar para el PRI y el gobierno" ( $L a$ Jornada, 10 de enero de 2000). En este sentido, el calificativo de "marranada" respecto de la decisión del TEPJF estaría presente durante toda la campaña electoral como un ejemplo crítico (véase Adrián Trejo, El Economista, 2 de junio de 2000 o Aurora Berdejo, Excélsior, 6 de junio de 2000). 
defensa efectuada desde el gobierno y el PRI, ${ }^{13}$ y la ambigüedad mostrada por el PRD, el IFE y el propio tribunal al momento de avalar la decisión; ${ }^{14}$

- Cuarta, la determinación de etiquetas: la decisión del pan de presentar como alternativa la incorporación del perfil sombreado del candidato, la segunda negativa del tribunal y, por último, la victimización realizada por Vicente Fox y la puesta en marcha de un 'chantaje institucional'. ${ }^{15}$

Dados estos elementos, la carencia de identidad institucional determinaba un clima general de desconfianza y facilitó que Vicente Fox pusiera sobre la mesa un 'chantaje institucional' que hubiese sido más difícil de desplegar si el TEPJF hubiese contado con una sólida identidad positiva: "Vicente Fox ha insistido en que será creíble un eventual triunfo de Francisco Labastida sólo si el margen de ventaja sobre el panista fuera de diez puntos o más. Los magistrados del TEPJF han interpretado esta declaración como una presión inaceptable del candidato presidencial panista, porque ellos son la última instancia y la única institución facultada constitucionalmente para declarar quién es presidente electo" ( $E l$ Heraldo de México, 5 de abril de 2000). Vicente Fox se asumía, no tanto como un candidato al que se le negó incluir su fotografía en la boleta, sino como una víctima más de un sistema autoritario que se resistía al cambio y para ello seguía utilizando las instituciones electorales (concretamente el TEPJF) en su provecho.

${ }^{13}$ Francisco Labastida, candidato del PRI, "instó [...al PAN] de manera fuerte y muy intensa a elevar el nivel de la contienda y dejar de un lado las expresiones de pillos que hizo [...Fox] a los magistrados del Tribunal" (La Jornada, 10 de enero de 2000).

${ }^{14}$ El PRD mantuvo una táctica de avalar al tribunal en lo federal, lo que se certifica cuando su candidato, Cuauhtémoc Cárdenas expresó su confianza hacia el TEPJF ( $E l$ Heraldo de México, 20 de abril de 2000) y criticarlo en las elecciones al D.F. -sobre todo a raíz de una controversia con el candidato a la jefatura de la ciudad, Andrés Manuel López Obrador quien declaró que "en México todavía no hay independencia en los tribunales” en referencia al TEPJF (Reforma, 14 de mayo de 2000). En el IFE hubo diferencias con respecto al tribunal, así, tras un apoyo continuo del consejero presidente, José Woldenberg, los consejeros Emilio Zebadúa (La Jornada, 28 de mayo de 2000) o Jaime Cárdenas (El Universal, 5 de junio de 2000) se mostraron críticos con la institución en diferentes momentos. En cuanto al tribunal, esta fue una decisión controvertida que tuvo el voto en contra de su presidente magistrado, José Luis de la Peza, y generó una discusión acerca de la existencia de un vacío legal al respecto.

15 "No podemos ignorar la estrategia foxpanista. Luego del debate preparan a los cruzados democráticos que vencerán el pecado mortal del fraude electoral. Van por todo desde que descalificaron al TRIFE" (Sergio Miranda, Ovaciones, 11 de mayo de 2000); "No ha dejado [...Fox] de criticar y desacreditar al TRIFE" (Raymundo Rivapalacio, Milenio y La Afición, 15 de mayo de 2000); "Confío plenamente -declaró Vicente Fox- en el IFE, espero que el Tribunal no intervenga” (El Heraldo de México, 21 de abril de 2000). 
Las consecuencias de esta dinámica pueden evaluarse a través de los cambios de posiciones respecto al tribunal en la prensa, así, mientras que antes del escándalo las noticias y comentarios periodísticos hacia el TEPJF tenían un perfil positivo, en enero y febrero del 2000 éstos comenzaron a mostrar una tendencia negativa, tal y como se ve en la gráfica II:

\section{Gráfica II}

Perfil positivo o negativo de las notas acerca del TEPJF en prensa septiembre 1999-febrero 2000

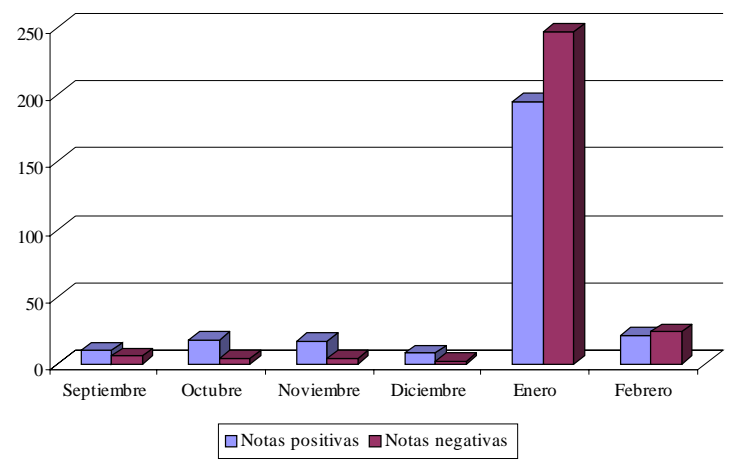

Fuente: Elaboración propia.

El escándalo tuvo una duración de aproximadamente un mes, por lo cual sus efectos sobre la identidad del TEPJF no fueron concluyentes, además, hay que destacar que, pese a que el crecimiento de notas negativas es relativamente más importante que el de las positivas, ambas superaron su media habitual y en el mes de febrero ya estaban igualadas, lo que manifiesta dos cosas: por un lado, que la construcción de una identidad positiva para el TEPJF comenzó a ser una preocupación para diversos actores políticos y sociales (la identidad institucional importa); y por otro, que la sociedad mexicana, a través de la prensa, manifiesta un compromiso no asentado frente a las decisiones institucionales.

El resultado final de la elección favoreció al agredido y a la postre presidente de la república, Vicente Fox, quien se disculpó frente al tribunal en el momento de recoger su certificación como presidente electo. ${ }^{16}$ Este hecho, así como la propia evolución de la institución, hacen que su posición actual previsiblemente haya

\footnotetext{
${ }^{16}$ En esta ocasión Vicente Fox señaló: “el IFE y el Tribunal han cumplido a cabalidad con la misión que la sociedad les asignó, lo que debe ser motivo de orgullo de todos los mexicanos" (La Jornada, 3 de agosto de 2000).
} 
variado hacia una tendencia positiva (o se haya reubicado en ésta). Sin embargo, ¿qué hubiese ocurrido con el tribunal en caso de que hubiese ganado el candidato del PRI? Por supuesto que esta cuestión no tiene respuesta pero el caso Fox versus TEPJF mostró claramente que la ausencia de identidad del TEPJF le hacía susceptible de ataques por parte de diversos actores políticos, lo que reforzaba el clima de desconfianza frente al sistema en su conjunto y podía llegar a cuestionar el proceso de cambio político. De este modo nos preguntamos: ¿cómo se manifiesta la falta de identidad del TEPJF?

\section{La identidad del TEPJF en el marco de las elecciones federales de 2000}

El análisis acerca de la identidad del TEPJF se sustentó en tres preocupaciones básicas: conocer hasta qué punto la institución era identificable por los ciudadanos; qué grado de confianza existía respecto a su actuación en las elecciones; y cuánta legitimidad la sustentaba. ${ }^{17}$ Este ejercicio tiene una limitación temporal (las elecciones del 2 de julio), sin embargo, muestra con claridad la importancia que tiene para las instituciones construir una identidad positiva, lo que podríamos llamar en términos comerciales una 'marca'.

\subsection{La ausencia de identificación o el desconocimiento social del TEPJF}

En primer lugar, 32 de 40 entrevistados dijeron sí conocer al tribunal electoral o haber oído hablar de él, tal y como se muestra en la gráfica III. Esta aparente popularidad de la institución venía, en principio, determinada por el grado de educación e información de nuestros entrevistados, así, de los cinco de nuestro grupo de control de clase popular sólo uno contestó afirmativamente a esta pregunta general. Sin embargo, el hecho de haber oído hablar del tribunal dista mucho de tener un conocimiento cabal del mismo, es decir, poder identificar cuáles son sus características.

${ }^{17}$ Con el fin de analizar estos puntos se diseñó una investigación articulada a partir de la realización de cuarenta entrevistas semiestructuradas a ciudadanos con credencial de elector residentes del D.F. La mayor parte de entrevistados, excepto cinco de un grupo de control de clase popular, fueron elegidos entre estratos de clase media al considerar a este sector social como el básico en la construcción de opinión pública. La selección se realizó bajo criterios de edad, género y preferencia político-partidaria, ya que este último aspecto se consideró vital al momento de evaluar el comportamiento institucional. 


\section{Gráfica III}

\section{Porcentaje de ciudadanos que han oído hablar del TRIFE-TEPJF}

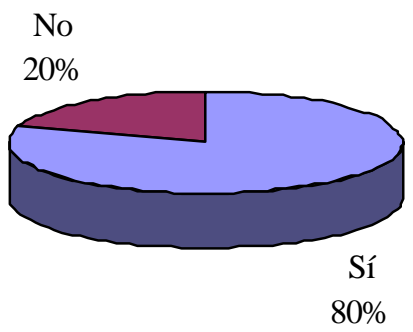

Fuente: Elaboración propia.

Cuando se preguntó a los entrevistados cuáles eran las funciones del tribunal electoral, las respuestas se agruparon en tres rubros:

Primero, quienes dijeron que su función era certificar las elecciones: "verificar que todo sea legal"; "ratificar que realmente las elecciones sean adecuadas"; "certificar las elecciones".

Segundo, aquellos que la identificaron como un mecanismo de control del proceso electoral y/o los partidos: "hacer que lo regulado por el IFE se cumpla, (...) no sé... mil cosas"; "que los partidos estén bien acreditados, nada chueco, que tengan buena solidez y todo eso"; "vigilar primero la manera en que se lleva a cabo el voto (...) que exista imparcialidad".

Tercero, quienes señalaron que se encargaba de canalizar protestas y penalizar a los partidos políticos: "es donde llegan todas las quejas de los partidos sobre las anomalías o irregularidades en las votaciones"; "sancionar a algún partido o algún candidato que se esté pasando".

De este grupo de respuestas, la primera y la tercera, que corresponden a las características centrales de la institución, fueron las menos señaladas, mientras que la segunda, de carácter más vago y que puede corresponder a cualquiera de las instituciones electorales, fue la más reseñada. Además, sólo cinco entrevistados reconocieron espontáneamente haberse informado a través de los medios de comunicación sobre el TEPJF, lo que explica el hecho de que la información sobre el mismo solía ser incompleta y a veces totalmente errónea (“el tribunal pertenece al IFE"). ${ }^{18}$

${ }^{18}$ Aunque a lo largo del documento sostengamos que el IFE es un ejemplo de construcción de identidad positiva, el hecho de que exista confusión entre éste y el TEPJF denota que la identidad del IFE tampoco está plenamente consolidada. Esto nos hace pensar la hipótesis -que no desarrollaremos en este trabajo- de que el IFE mantiene cierta centralidad en el cambio político mexicano por lo que monopoliza la visión acerca de lo electoral, dificulta la construcción de identidad para otras instituciones y hace 
Esto permite ver que el TEPJF no tiene una identidad pública definida, es decir, no cuenta con unos límites claros que marquen una diferenciación del mismo con respecto a otras instituciones del Estado, especialmente con otras instituciones electorales. Sin embargo, la mayor parte de entrevistados tenían referencias de él y estaban dispuestos a emitir juicios de valor sobre la institución. Esto nos indica que la carencia de identidad-identificación no significa inexistencia, sino una diferenciación de baja intensidad por la que en una situación de entrevista (así como en otras situaciones críticas como puede ser una toma de posición frente a un escándalo como el caso Fox versus TEPJF) los sujetos construyen un discurso basado en las evocaciones que la palabra TRIFE-TEPJF suscita, así como, en sus tradiciones y experiencias políticas.

De este modo, decidimos comparar la imagen del tribunal con la de dos evocaciones que el propio nombre Tribunal Electoral contrae: el IFE, que supuestamente representaba el polo positivo en el imaginario de nuestros entrevistados (la identidad positiva); y los tribunales ordinarios de justicia que, seguramente, representaban un polo negativo (la identidad negativa). En confirmación con nuestra hipótesis, y al momento de asociar a estas tres instituciones con una serie de nociones, tanto positivas como negativas, los resultados fueron los que se muestran en la gráfica IV.

\section{Gráfica IV}

Asociación de las palabras TRIFE, TEPJF, IFE y tribunales con nociones negativas $\mathrm{y}$ positivas

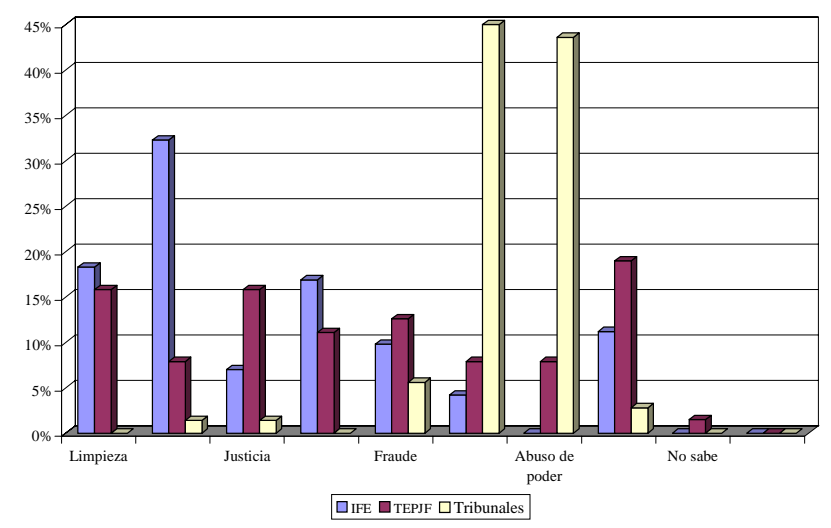

Fuente: Elaboración propia.

que su ausencia de identidad completa no revierta en problemas de identificación tanto como de identificación basada en conocimientos reales. 
$\mathrm{Al}$ interpretar la gráfica IV, concluimos que el IFE tiene una tendencia a presentarse como una institución avalada por una identidad positiva en tanto es asociada con las nociones de democracia, limpieza, independencia y justicia (aunque también, en cierta medida, con la noción de políticos y fraude lo que nos hace hablar de tendencia y no de una identidad sólida); los tribunales se consolidaron en una imagen altamente negativa en tanto la mayor parte de entrevistados los asoció con corrupción y abuso de poder; mientras que el tribunal electoral estaba carente de una imagen sólida y su tendencia de posicionamiento no era tan evidente como la del IFE, es decir, fluctuaba entre los dos polos a los cuales sus propias siglas evocan sin situarse con claridad en un extremo o en otro; como vemos, es asociado de igual modo con limpieza y justicia que con políticos y fraude. ¿Qué consecuencias tenía esta situación de indefinición sobre la confianza que los ciudadanos podían tener acerca de la institución?

\title{
4.2 La confianza en el TEPJF
}

Para responder a la pregunta anterior, en primer lugar cuestionamos a los entrevistados si consideraban que era positiva la existencia de una institución como el TEPJF. La pregunta, al incluir el como, se formuló de manera intencionalmente ambigua de modo que la respuesta fue notablemente afirmativa (véase la gráfica v), lo que demuestra la demanda, por parte de la sociedad, de organismos predecibles o confiables que satisfagan determinadas expectativas y deseos.

\author{
Gráfica V \\ Respuestas a la pregunta: \\ ¿considera positiva la existencia de una institución \\ como el TRIFE-TEPJF?
}

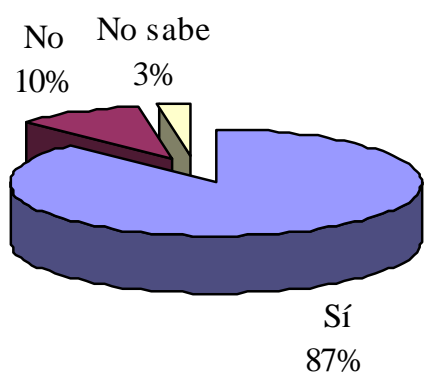

Fuente: Elaboración propia. 
Esta demanda de confianza, y que el TEPJF pudiera satisfacerla positivamente, se debía reforzar con una segunda pregunta acerca de si el tribunal podía favorecer a un partido político determinado frente a otros, es decir, no sólo se cuestionaba sobre la parcialidad de la institución sino que se indagaba acerca de qué comportamiento es el que los sujetos esperaban (en términos de predicción) de ésta. En contraste con la pregunta anterior la respuesta fue verla como un organismo parcial, es decir, se esperaba que no actuara de manera acorde con las expectativas sociales (véase la gráfica vI).

\section{Gráfica vI \\ Respuesta a la pregunta: \\ ¿el TRIFE-TEPJF puede favorecer a un partido \\ político determinado?}

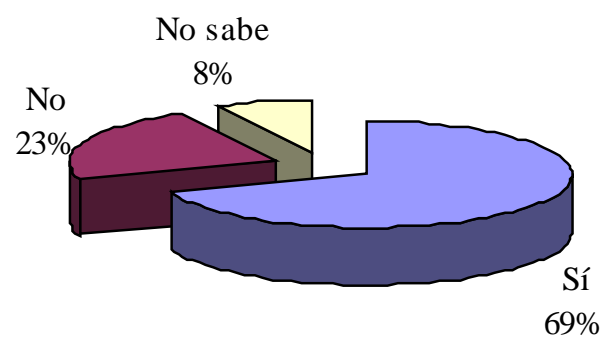

Fuente: Elaboración propia.

Esto nos puede llevar a asociar falta de identidad con una confianza negativa, es decir, con el hecho de que los sujetos predicen que el comportamiento de la institución no cumplirá sus expectativas. Sin embargo, la interpretación de esta respuesta y la anterior es más complicada. La aparente contradicción entre ambas se solucionó cuando se indagó a los entrevistados con cuál de una serie de afirmaciones estaban más de acuerdo. Afirmaciones que correspondían a tres tipos de discurso a los que los entrevistados podían enfrentarse en una situación crítica como un escándalo (los tres eran igualmente sesgados hacia una posición u otra frente al sistema político): el primero, suponía una predicción negativa; el segundo, una suerte de impredicción; y el tercero, una predicción positiva. Los resultados se muestran en la gráfica VII. 
Estos resultados nos hicieron concluir que los ciudadanos insertaban al TEPJF en una dinámica global de cambio político inacabado por la cual, si bien estaban dispuestos a dotarle de cierta confianza, ésta no era plena sino que se sujetaría a juicios futuros sustentados en acciones concretas, es decir, la predicción tendría que justificarse a partir de la reiteración de acciones conocidas. Podemos hablar, así, de la presencia de una desconfianza preventiva.

Es importante resaltar que un mínimo de los entrevistados estuvo dispuesto a desplegar un discurso que avalara a la institución, mientras que un número más considerable mantuvo la desconfianza como actitud prevaleciente. En este sentido, casos como el de Fox versus TEPJF podían fácilmente inclinar a la opinión pública hacia la desconfianza institucional en tanto el discurso de la desconfianza tiene mayor potencialidad que el de la confianza al momento de influir sobre un mayoritario discurso de la duda. Es decir, ante la falta de identidad y en un sistema político con fuerte presencia de desconfianza, los escándalos provocan juicios que vienen a resumirse en la primera posición: predecir que las instituciones no cumplirán las expectativas sociales. A partir de aquí nos preguntamos: ¿con qué legitimidad social cuenta el TEPJF?

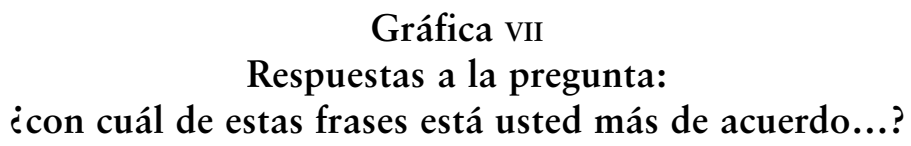

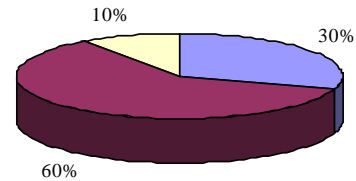

Fuente: Elaboración propia. $\square$ En México, los tribunales de justicia no funcionan como deberían, por tanto, el TEPJF no cumplirá con las expectativas depositadas por la sociedad

$\square$ En México estamos avanzando para que los tribunales funcionen bien y las elecciones sean cada vez más limpias y justas, por eso, hay que confiar en la labor del TEPJF

$\square$ En México, las elecciones son limpias y justas, por lo tanto, el TEPJF cumplirá bien sus tareas 


\subsection{La legitimidad social del TEPJF}

La asociación con determinados valores fue tomada como el indicador del grado de legitimidad de las instituciones. Así, consideramos que la tendencia positiva mostrada por el IFE indicaba una evolución hacia la aceptabilidad de la institución basada en sus acciones y progresivo conocimiento que la sociedad tiene respecto de ella; del mismo modo los valores negativos con que se asocia a la noción de tribunales demuestran el alto grado de ilegitimidad de las instancias ordinarias de impartición de justicia. La cuestión, para una institución aún no identificable como el TEPJF, era averiguar por qué la sociedad legitima o no a una institución determinada y en cómo influía esto en las características formales del tribunal.

Los entrevistados dijeron legitimar al IFE porque cumplía con cinco expectativas o satisfacía cinco deseos:

- Es una institución democrática en tanto nacida y vinculada con la sociedad, ("nosotros como sociedad civil le hemos ido marcando pautas");

- Es una institución autónoma que no depende del gobierno ni de la clase política, ("como que la independencia le da más credibilidad");

- Es transparente, limpia y honrada porque así lo demuestran sus acciones y quienes forman la institución ("lo preside alguien honrado");

- Es responsable porque cumple con su deber y rinde cuentas ante la sociedad (“tiene la vista de todo el país”);

- Es eficiente porque cuenta con profesionales ("me parece que están bien organizados”).

Por otra parte, los tribunales quedaban deslegitimados por cuatro aspectos que niegan las expectativas sociales sobre estas instituciones:

- No son democráticos sino corruptos y discrecionales al estar asociados con los poderosos ("quien tiene más dinero tiene otro tipo de justicia");

- Abusan del poder en tanto se ligan a intereses particulares y no generales ("no nos dan alguna razón para defendernos");

- Actúan con secretismo dado que avalan fraudes ("todo está plagado de corrupción”);

- Están compuestos, no por profesionales, sino por gente ligada a intereses políticos y económicos que actúa con falta 
de honradez e impunidad ("protegen los intereses de la gente que tiene poder").

Esta serie de interpretaciones acerca de cómo se constituye una identidad positiva frente a una negativa nos da cuenta de las expectativas sociales en México no en términos de predictibilidad, ya que es tan predecible la actuación del IFE como la de los tribunales, sino en términos de los deseos y características a los que una institución legítima debe responder.

La utilidad de este análisis respecto al TEPJF es doble: por un lado, establece las pautas discursivas y los modos en que la institución habría de presentarse ante el público al momento de construir una identidad positiva (su marca). En este artículo, esto es lo que menos nos interesa. Por otro lado, el análisis sirve para establecer en qué medida las características propias de la institución (sus procedimientos) se ajustan a las necesidades de legitimidad institucional. Con el fin de resolver este segundo aspecto formulamos dos cuestiones básicas.

En primer lugar, preguntamos a nuestros entrevistados qué institución debería certificar la elección presidencial. Partiendo de un discurso tendente a legitimar el IFE, así como, identificar democracia con ciudadanía y eficacia con profesionalismo, las respuestas se agruparon en esos términos, donde apareció la noción de tribunal como certificadora de las elecciones con una baja intensidad (véase la gráfica VIII).

\section{Gráfica VIII \\ Respuesta a la pregunta: ¿quién debería certificar las elecciones?}

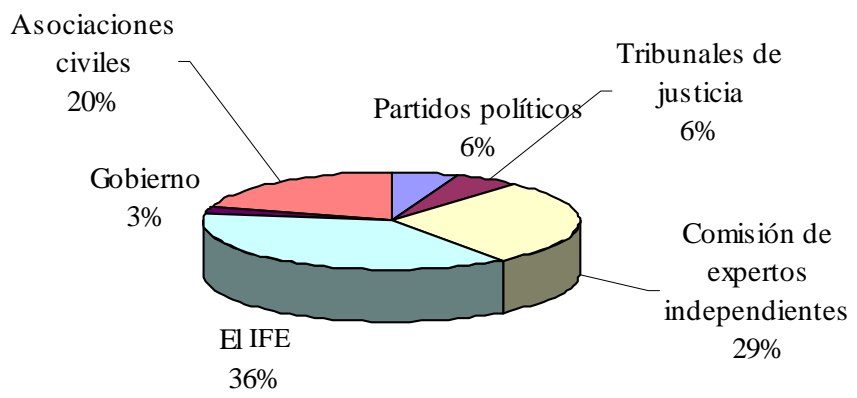

Fuente: Elaboración propia. 
Estas respuestas suponen un problema en la construcción de una identidad positiva para el TEPJF en tanto esta institución es, al fin y al cabo, un tribunal. Sin embargo, también podría tener la ventaja de considerar a los magistrados como los únicos expertos en materia de controversia electoral. Esto nos manifiesta el hecho de que los procedimientos institucionales y la concreción de una identidad institucional positiva no responden a un ajuste perfecto, sino que existen contradicciones entre las características formales de una institución y los deseos del público. Esto fue más notable con una segunda pregunta.

Se cuestionó a los entrevistados acerca del método de selección de los magistrados que componen el tribunal de una manera intencionalmente simplificada: "Los miembros del TRIFE son nombrados por los propios jueces bajo acuerdo mayoritario del Senado de la República, ¿cree que es una buena manera de elegir sus miembros?" Las respuestas se distribuyeron tal y como lo muestra la gráfica IX.

\author{
Gráfica IX \\ Respuesta a la pregunta: \\ ¿le parece correcto el modo de elegir los miembros \\ del TRIFE, TEPJF?
}

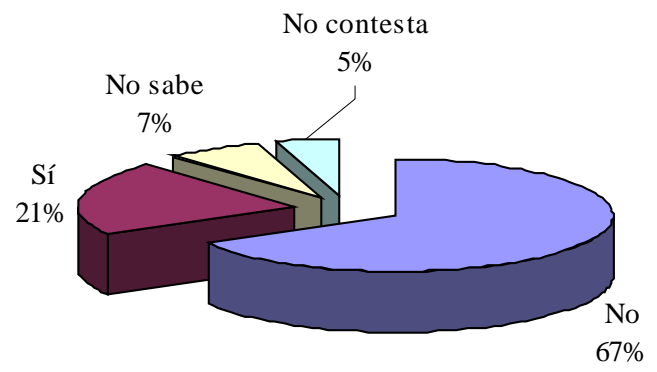

Fuente: Elaboración propia.

Los ciudadanos parecen poco dispuestos a legitimar una institución que emana de dos organismos con una identidad negativa: tribunales (más allá que se trate de la Suprema Corte de Justicia de la Nación) y clase política (aunque ésta sea encarnada por representantes electos en el Senado). Es decir, el procedimiento de selección de los magistrados, por más que salvaguarde su independencia y se establezca bajo un método mayoritario, en prin- 
cipio no cumple las expectativas de la sociedad, lo que muestra que las acciones institucionales son importantes al momento de construir legitimidad y no sólo, o no principalmente, las características propias de la institución. Es decir, en tanto la propia dinámica institucional sirva para cumplir determinadas expectativas éstas serán legitimadas o no, más allá de que sus características originales tiendan a conformar una identidad positiva o negativa.

\section{Conclusiones}

La situación que vivió el TEPJF en la campaña electoral del 2000 es un ejemplo ilustrativo para el estudio de la identidad institucional pues muestra cuatro aspectos acerca de este fenómeno: primero, que en democracias donde no existe un compromiso institucional asentado las instituciones necesitan, no sólo generar este compromiso entre la clase política (incluidos los medios de comunicación), sino construir una identidad ('marca') que facilite su defensa ante situaciones críticas (las inmunice); segundo, que el desconocimiento institucional no es un factor que impida la emisión de juicios sociales acerca del desempeño institucional, sino un hecho que hace que estos juicios sean fácilmente manipulables, por lo que es necesario dar a conocer las instituciones para construir un discurso social sólido sobre las mismas; tercero, que el origen y los procedimientos institucionales no se ajustan perfectamente a las expectativas sociales, por lo que debemos diferenciar entre niveles de legitimidad y generar estrategias de comunicación que resalten y rearticulen los atributos institucionales respecto de las demandas de la sociedad; y cuarto, las instituciones necesitan que su buen desempeño no sea pasajero (dependiente de personas o de la suerte) sino una característica propia de su diseño (Putnam, 1994: 74), de este modo, la identidad institucional se fundamenta en el conocimiento cotidiano que la sociedad tiene de las instituciones, es decir, y para el caso que nos ocupa, el TEPJF necesita romper -a través de sus acciones- la lógica de la desconfianza preventiva que caracteriza a la sociedad mexicana. Aunque una institución no sea un producto en un mercado, a través de este análisis parece evidente que un sistema democrático no sólo se basa en que las instituciones funcionen sino en su capacidad de trasmitir este hecho a la ciudadanía. 


\section{Bibliografía}

Ames, B. (1970), "Bases de apoyo del partido dominante en México", en Revista Foro Internacional, XI (1), Colmex, México.

Beetham, D. (1992), The legitimation of power, Macmillan Press, London.

Cansino, C. (2000), "El léxico del cambio político", en Revista del Instituto Electoral del Estado de México, Apuntes electorales, 1(3), IEEM, México.

Durand Ponte, V. (1997), "Cultura política de masas y cambio en el sistema político: el papel de la ambigüedad cultural”, en Revista Mexicana de Sociología, LIX (1), IIS-UNAM, México.

Estévez, Federico y Mario Ramírez Rancaño (1985), “Leña del árbol caído: el cambio socioeconómico y la dirección del voto”, en Revista Estudios Políticos, Nueva Época, 4 (1), enero-marzo, México.

Gil Villegas, F. (1984), "La crisis de legitimidad en la última etapa del sexenio de José López Portillo", en Revista Foro Internacional, xxv (2), Colmex, México.

González Casanova, P. (1976), La democracia en México, Era, México.

IFE (2000), Estudio de evaluación de spots de radio y televisión correspondientes a la campaña de promoción de la participación ciudadana, julio, IFE, México.

Jiménez Sánchez, F. (1994), Una teoría sobre el escándalo politico, Instituto Juan March de Estudios e Investigaciones, Madrid.

Labastida, J. (1997), "Proceso político y dependencia (19701976)", en Revista Mexicana de Sociología, XXXIX (1), IISunAM, México. 
Linz, J. (1970), “An authoritarian regime: Spain”, en Allardt y Rokkan, Mass Politics, Free Press, New York.

March, J. y J. Olsen (1997), El redescubrimiento de las instituciones, la base organizativa de la política, Fondo de Cultura Económica, México.

Molinar Horcasitas, J. (1993), "Escuelas de interpretación del sistema político mexicano", en Revista Mexicana de Sociología, LV (2), IIS-UNAM, México.

_ (1996), "Renegociación de las reglas del juego: el Estado y los partidos políticos" en M. Serrano y V. Blumer, La reconstrucción del Estado, México después de Salinas, Fondo de Cultura Económica, México.

Pacheco Méndez, G. y J. Reyes del Campillo (1987), "La distribución de candidaturas a diputados en el PRI", en Revista Argumentos, núm. 2, noviembre, UAM, México.

Pereyra, C. (1984), “La desigualdad política”, en R. Cordera (coord.), La desigualdad en México, Siglo xxI, México.

Pérez Fernández, G. (1991), “Gobernabilidad y sistema político en México", en Revista Latinoamericana de Ciencias Sociales, $2^{a}$ época, 1 (1), FlACSO-Costa Rica, Costa Rica.

Peschard, J. (1997), “El IFE: Naturaleza y estructura”, en Revista Estudios Parlamentarios del Congreso, 1 (10), México.

Putnam, R. (1994), Para hacer que la democracia funcione. La experiencia italiana en la descentralización administrativa, Galac Editorial, Caracas.

Ramos Oranday, R. (1985), “Oposición y abstencionismo en las elecciones presidenciales 1964-1982” en P. Gonzáles Casanova, Las elecciones en México evolución y perspectiva, Siglo xxi, México.

Sartori, G. (1995), Partidos y sistemas de partidos, Alianza editorial, Madrid. 
Schedler, A. (1999), "Percepciones públicas en el fraude electoral en México", en Perfiles Latinoamericanos, 8 (14), FLACSOMéxico, México.

— (2000), "Incertidumbre institucional e interferencias de imparcialidad: el caso del Instituto Federal Electoral", en Revista Política y Gobierno, VII (2), CIDE, México.

Segovia, R. (2000), "El fin del modelo modernizador autoritario" [1974], en R. Segovia, Lapidaria política, Fondo de Cultura Económica, México.

TEPJF (2000), El sistema mexicano de justicia electoral. Proceso electoral federal, 1999-2000, TEPJF, México.

Woldenberg, J. (1992), "El proceso electoral en México en 1988 y su secuela", en M. Alcántara, México frente al umbral del siglo XXI, CIs-Siglo XXI, México.

Enviado: 25 de junio de 2001 Aceptado: 13 de julio de 2001 
